\title{
MARGINAL ACCURACY OF DIFFERENT CAD/CAM MONOLITHIC CROWNS CEMENTED ON IMPLANT ABUTMENTS.
}

\author{
Amira Mohamed Elsharkawy*
}

\begin{abstract}
Purpose: The aim of this study was to evaluate the marginal adaptation of four monolithic $\mathrm{CAD} / \mathrm{CAM}$ all-ceramic crowns cemented on implant abutments after fatigue loading.

Materials and methods: A lower right first molar was designed in CAD/CAM software and twenty crowns were machine milled using four different monolithic ceramic blocks $(n=5)$ : Group I: Vita Enamic (V.enamic), GroupII: IPS E-max CAD(e.max), GroupIII: Celtra Duo(CD), GroupIV: Functional explore (f.explore). The crowns were fabricated using CAD/CAM system. All crowns were cemented on implant abutments using self adhesive resin cement. Vertical margin gap distance of all crowns was measured using a digital microscope. All the samples were subjected to fatigue cyclic loading for 75.000 cycles. The vertical marginal gap distance for all samples were subsequently remeasured after the fatigue loading testing. Data were collected, tabulated and statistically analyzed.
\end{abstract}

Results: The highest marginal gap mean value was for $\boldsymbol{C D}$ group followed by $\boldsymbol{f}$ Explore group then $\boldsymbol{V}$. Enamic group while the lowest marginal gap mean value was recorded with $\boldsymbol{e}$.max group and this was statistically significant between the groups $(\mathrm{P}=0.0013<0.05)$. The total marginal gap mean values with all types of ceramics were higher after aging than before with significant difference $(\mathrm{P}=<0.0001<0.05)$.

Conclusions: all-ceramic crown materials that are used for chair-side CAD/CAM systems demonstrated clinically acceptable marginal adaptations. V. Enamic and LD provided better marginal fit than $\mathrm{CD}$ and f.explore zirconia. Fatigue loading had a detrimental influence in the vertical marginal gap distance for all ceramic types except f.explore zirconia.

KEY WORDS: Marginal accuracy, monolithic crowns, implant abutments .

\section{INTRODUCTION}

Computer-aided design/computer-assisted manufacturing (CAD/CAM) process allows the chairside fabrication of implant-supported prostheses with satisfactory marginal gap. ${ }^{(1,2)}$ There are several types of ceramics used in posterior fixed restorations with similar survival rates to those of conventional restorative materials. ${ }^{(3,4)}$

\footnotetext{
* Associate Professor, Fixed Prosthodontics, Faculty of Dentistry, 6th of October University, Giza, Egypt
} 
Gracis et al ${ }^{(5)}$ classified the ceramic material according to presence of glass-matrix phase (glassmatrix ceramics) or absence (polycrystalline ceramics) or whether the material contains an organic matrix highly filled with ceramic particles (resin-matrix ceramics). The chosen ceramic materials belong to three different ceramic families

IPS e max CAD belongs to glass-matrix ceramics and characterized by enhanced physical properties and translucency due to the high concentration of refined lithium disilicate crystals. ${ }^{(5,6)}$

A zirconia-containing lithium silicate (ZLS) belongs to glass-matrix ceramics ${ }^{(7)}$ and new generation of materials intended for $\mathrm{CAD} /$ CAM use. Its composition depends on a lithiumsilicate (Li2SiO3) glass ceramic reinforced with $10 \%$ of zirconium dioxide $(\mathrm{ZrO} 2)^{(8)} ;$ after final crystallization process, fine grained microstructure (Li2O-ZrO2-SiO2) have been established combining a positive mechanical properties of zirconia and aesthetic appearance of glass ceramics. ${ }^{(8,9)}$

F.explore zirconia belongs to polycrystalline ceramics. The nano zirconia powder is newly produced giving a unique ability to continually develop new and specialized zirconia for the dental market. F.explore is a multi-coloured zirconia block with five layers of color that have different light transmittance capabilities, Partially sintered zirconia blocks were selected in this study as the CAM processing with the softer pre-sintered material and high fracture toughness after sintering to resist chippings. ${ }^{(6,10)}$

Vita Enamic belongs to resin-matrix ceramics; It contains a hybrid structure ; two interpenetrating networks of ceramic and polymer that combines ceramic and polymer properties. It's modulus of elasticity resembling the natural human dentin. The most prominent property is the easy machinability of the material which takes the leading position among all blocks used. ${ }^{(5,11,12)}$
Marginal adaptation and fatigue failure are major factors that may disturb the long-term success of fixed prosthodontic restorations ${ }^{(13)}$, consequently, the misfit between the abutment and restoration lead to bacteria colonization, which may conceivably cause inflammatory reactions in the peri-implant soft tissues. ${ }^{(14,15)}$ Therefore the purpose of the present study was to evaluate the marginal adaptation of different monolithic CAD/CAM allceramic crowns cemented on ready-made titanium abutments after thermal and mechanical fatigue loading. The null hypothesis was that the vertical marginal gap distance of molar crowns will not be affected by the type of the ceramic material or the fatigue loading.

\section{MATERIALS AND METHODS}

Twenty fixture implant analog (Neobiotech C0., Ltd. Guro-gu, Seoul, Korea) were screwed to implant impression copings (IS Hexed Pick-up Impression coping 4.0/Long). The implant analogs were centralized -using a dental parallelometer- in a polyvinyle tube with $13 \mathrm{~mm}$ diameter and fixed with acrylic resin (Cold cure denture base material, Acrostone Dental Factory). The impression copings were removed and straight IS Cemented type Abutments (4.5 diameter $* 1.0 \mathrm{~mm}$, abutment length: $4.0 \mathrm{~mm} \mathrm{Hex}, 8^{\circ}$ convergence angle) (Neobiotech $\mathrm{C} 0$., Ltd. Guro-gu, Seoul, Korea) were screw attached to the implant analogs according to manufacturer's directions, figure $1 \mathrm{~A}$. The abutments were shortened to $4 \mathrm{~mm}$ using diamond disc mounted on a lowspeed hand piece held by a parallelometr, figure 1B.

The screw holes of the abutments were filled with light cured composite (Filtek Z350 XT Universal Restorative System (3M-ESPE AG Dental products ST. Paul, MN 55144 USA).

The twenty abutments were sprayed with a special spay (Renfert GmbH Industriegbiet 78247 Hilzingen/Germany), then scanned using Scan Box (Smart Optics Sensortechnik GmbH, Germany) and transferred into the CAD/CAM software (InLab 
version 4.0; Sirona) except f.explore group the design was sent to their milling machnine (MDX50 BenchtopCNC Mill-Ronald DC, Japan). A lower right first molar (figure:2) was designed for all groups and set to allow $50 \mu \mathrm{m}$ cement space thickness and twenty crowns were machined milled using four different ceramic materials ; $(n=5)$ (The manufacturers' information of the monolithic ceramics used in this study was shown in Table 1):

Group 1(N=5): Vita Enamic (V.enamic) (VITA Zahnfabrik, Bad Säckingen, Germany). Finished with rubber (Eve America; Naples, FL);

Group 2 (N=5): IPS E-max CAD(e.max) (Ivoclar Vivadent, Schaan, Liechtenstein). Sintered and finished a with a glaze cycle (Programat P300; Ivoclar Vivadent);

Group 3 (N=5): Celtra Duo (CD) (Dentsply DeTrey, Konstanz, Germany); Crystallization and glazing process were performed in a furnace (Programat P310; Ivoclar Vivadent).

Group 4 (N=5): Functional explore (f.explore) (Shenzhen Upcera Dental Technology ; Co Hightech Industry Park, Nanshan District, Shenzhen, Guangdong, China. Sintering was performed in (Tabeo-1/M/Zircon-100, Mihm Vogt, Germany) by Advanced Dental Studio - Egypt.

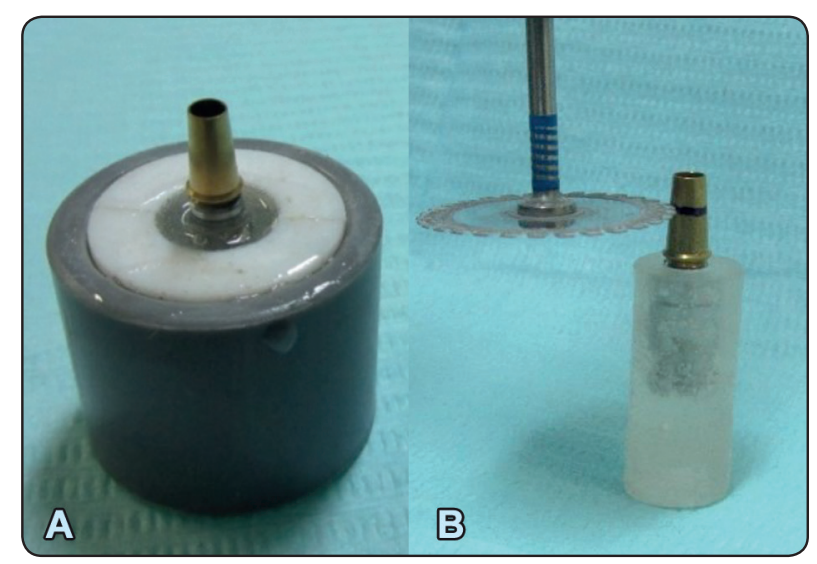

Fig. (1) A: Cemented Abutment was screw attached to the implant analog. B: The abutment was shortened to 4 mm using diamond disc mounted on a low-speed hand piece held by a parallelometr.
The sintering process was preceded in the Tabeo High-temperature furnace (Mihm Vogt $\mathrm{GmbH}$, Germany) by using the preset program of F. Explore as recommended by manufacturer. All twenty abutments were sand blasted by $50-\mu \mathrm{m}$ aluminum oxide particles (Renfert, Hilzingen, Germany) at a distance of $10 \mathrm{~mm}$ and steam cleaned (Steamer X3; AmannGirrbach, Charlotte, NC).

Before cementation, the fitting surface of each ceramic crown was treated according to the manufacturer's recommendations. For f. explore group; the inner surfaces of the zirconia crowns were air born particle abraded by $50 \mu \mathrm{m} \mathrm{Al} 2 \mathrm{O} 3$ particles at 1 bar pressure then ultrasonically cleaned and air dried. For CD groups, the inner surfaces of the crowns were washed with ethanol, treated with $5 \%$ hydrofluoric acid gel (Ceramic etching gel; Ivoclar Vivadent) for 20 seconds, and then washed with water. After removing the residual acid with water, they were air-dried and coated with silane coupling agent (Monobond N; Ivoclar Vivadent). For v.enamic group, the inner surfaces were washed with ethanol, treated with $5 \%$ hydrofluoric acid gel (Ceramic etching gel; Ivoclar Vivadent) for 60 seconds, and washed with water for 60 seconds. Afterwards, they were air-dried for 20 seconds and coated with silane (Monobond N; Ivoclar Vivadent).

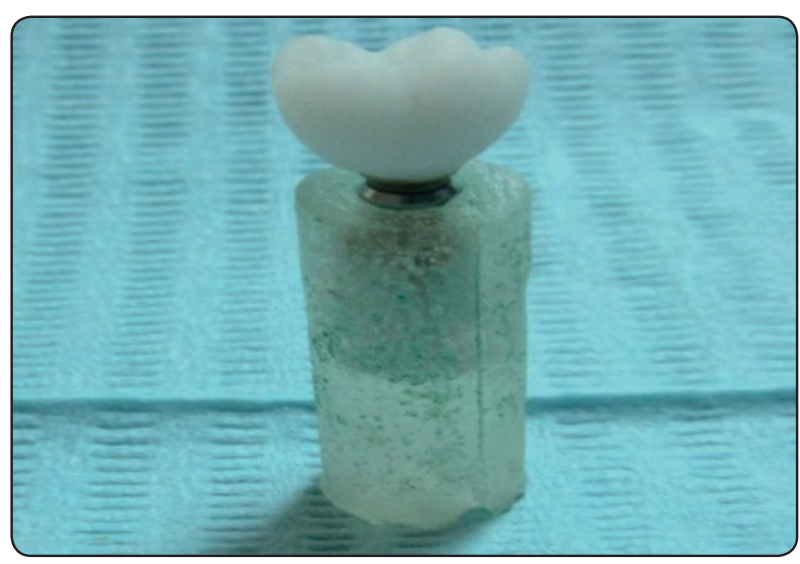

Fig. (2) Machine milled lower right first molar . 
TABLE (1): All-ceramic crown materials used in the study

\begin{tabular}{|c|c|c|}
\hline Material & Description, properties \& composition & Manufacturer \\
\hline $\begin{array}{l}\text { hybrid ceramic } \\
\text { (Vita Enamic) } \\
\text { (groupI) }\end{array}$ & $\begin{array}{l}\text { Double network hybrid ceramic block, Shade 3M2-HT EM-14 } \\
\text { Flexural strength : } 150-160 \mathrm{MPa} \\
\text { Fracture toughness: } 1.5 \mathrm{MPa} \mathrm{m}^{1 / 2} \\
\text { Elastic modulus : } 30 \mathrm{GPa} \\
\text { Composition of the ceramic part : (86 wt\% / } 75 \text { vol\%) } \\
\text { Silicon dioxide } \mathrm{SiO} 258-63 \% \\
\text { Aluminum oxide } \mathrm{A} 12 \mathrm{O} 320-23 \% \\
\text { Sodium oxide } \mathrm{Na} 2 \mathrm{O} 9-11 \% \\
\text { Potassium oxide } \mathrm{K} 2 \mathrm{O} 4-6 \% \\
\text { Boron trioxide } \mathrm{B} 2 \mathrm{O} 30.5-2 \% \\
\text { Zirconium dioxide } \mathrm{ZrO} 2<1 \% \\
\text { Calcium oxide } \mathrm{KaO}<1 \% \\
\text { Composition of the polymer part : (14 wt } \% \text { / } 25 \text { vol\%) } \\
\text { UDMA (urethane dimethacrylate) TEGDMA (triethylene glycol dimethacrylate) }\end{array}$ & $\begin{array}{l}\text { VITA Zahnfabrik } \\
\text { Germany }\end{array}$ \\
\hline $\begin{array}{l}\text { (group II) } \\
\text { Lithium-disilicate } \\
\text { glass } \\
\text { ceramic } \\
\text { (IPS e. max CAD) } \\
\text { (group II) }\end{array}$ & $\begin{array}{l}\text { Lithium disilicate glass-ceramic block } \\
\text { Flexural strength : } 360 \pm 60 \mathrm{MPa} \\
\text { Fracture toughness: } 2.0-2.5 \\
\text { Elastic modulus : } 95 \pm 5 \mathrm{GPa} \\
\text { Composition in } W \text { t\%: } \\
\text { Silicon dioxide } \mathrm{SiO} 257.0-80.0 \\
\text { Lithium dioxide } \mathrm{Li} 2 \mathrm{O} 11.0-19.0 \\
\text { Potassium oxide } \mathrm{K} 2 \mathrm{O} 0.0-13.0 \text { Phosphorus } \\
\text { pentoxide } \mathrm{P} 2 \mathrm{O} 50.0-11.0 \\
\text { Zirconium dioxide } \mathrm{ZrO} 20.0-8.0 \\
\text { Zinc oxide } \mathrm{ZnO} 0.0-8.0 \\
\text { Other \& coloring oxides } 0.0-12.0\end{array}$ & $\begin{array}{l}\text { Ivoclar Vivadent } \\
\text { Schaan, } \\
\text { Liechtenstein }\end{array}$ \\
\hline $\begin{array}{l}\text { Zirconia-reinforced } \\
\text { Lithium Silicate } \\
\text { (ZLS)Celtra duo }\end{array}$ & $\begin{array}{l}10 \% \text { zirconium dioxide (ZrO2) in highly dispersed form in the glass phase of the } \\
\text { ceramic blocks. } \\
\text { Flexural strength : } 370 \mathrm{MPa} \\
\text { Fracture toughness : } 2.56 \mathrm{MPa} \mathrm{m}^{1 / 2} \\
\text { Elastic modulus : } 70 \mathrm{GPa} \\
\text { Composition of the ceramic part } \\
\text { Zirconia } 10 \% \text { Silica, Lithium metasilicate and phosphate crystals } 58 \%\end{array}$ & $\begin{array}{l}\text { Dentsply DeTrey, } \\
\text { Konstanz, Germany }\end{array}$ \\
\hline $\begin{array}{l}\text { Yttria -stabilized } \\
\text { tetragonal zirconia } \\
\text { polycrystalline } \\
\text { (Upcera ) } \\
\text { (group VI) }\end{array}$ & $\begin{array}{l}\text { Upcera Zirconia , specialized for Full Contour Zirconia restorations Multi } \\
\text { Layered Zirconia disc with } 98.5 \mathrm{~mm} \text { diameter and } 18 \mathrm{~mm} \text { thickness, shade A } \\
\text { light } \\
\text { Flexural strength : } 1125 \mathrm{MPa} \\
\text { Fracture toughness :5.1 } \mathrm{MPa} \mathrm{m}^{1} \frac{2}{2} \\
\text { Elastic modulus : } 214 \mathrm{GPa} \\
\text { Composition in } \mathbf{W t} \% \text { : } \\
\text { Zirconium dioxide } \mathrm{ZrO} 2+\mathrm{HfO} 290-95 \% \\
\text { Yttrium Oxide } \mathrm{Y} 2 \mathrm{O} 35-8 \% \\
\text { Other oxides } \mathrm{CaO}, \mathrm{MgO} 0-2 \%\end{array}$ & $\begin{array}{l}\text { Shenzhen Upcera } \\
\text { Dental Technology } \\
\text { Co, China }\end{array}$ \\
\hline
\end{tabular}


For e. max group, the inner surfaces were treated with 5\% hydrofluoric acid gel (Ceramic etching gel; Ivoclar Vivadent) for 20 seconds, washed with water, air-dried, and coated with silane (Monobond $\mathrm{N}$; Ivoclar Vivadent).

All crowns were cemented with adhesive resin cement (RelyX Ultimate; 3M ESPE). A static load of $3 \mathrm{Kg}$ was applied on the occlusal surface of the cemented crowns using a specially designed loading device. The excess cement was removed, and light curing was done from each surface for 20 seconds using light curing unit (Astralis 3, Ivoclar Vivadent, Liechtenstein) with an output power of $600 \mathrm{~mW} /$ $\mathrm{cm} 2$. The load was sustained for 10 minutes.

\section{Vertical marginal gap distance measurements:}

Each sample was snapped using USB Digital microscope with a built in camera (Scope capture Digital microscope, Guangdong, China) connected with an IBM compatible personal computer using a fixed magnification of X35. A digital image analysis system (Image J 1.43U, National Institute of Health, USA) was used to measure the vertical marginal gap distance between all abutments and their corresponding supersructures before and after fatigue loading and thermocycling. For all samples, five equidistant landmarks along the cervical circumference for buccal, palatal, mesial and distal surfaces of each crown as shown in figure:3. The data obtained were collected, tabulated and then statistically analyzed.

\section{Cyclic fatigue loading}

Mechanical aging was performed using a programmable logic controlled equipment; the newly developed four stations multimodal ROBOTA chewing simulator* combined with thermocyclic system operated on servo-motor (Model ACH-09075DC-T, AD-TECH TECHNOLOGY CO., LTD., GERMANY) ROBOTA chewing simulator has four chambers simulating the vertical and horizontal movements all together in the thermodynamic condition. Each of the chambers contains an upper Jackob's chuck as hardened steel antagonist holder that can be tightened with a screw and a lower plastic sample holder in which the specimen can be embedded.

The specimens were embedded in chemical cured acrylic mold which in turn fixed by tightening screw to teflon holder in the lower part of simulator. A weight of $5 \mathrm{~kg}$, comparable to $49 \mathrm{~N}$ of chewing force was exerted. The test was repeated 75,000 times to clinically simulate the 6 months chewing condition, according to previous study. ${ }^{(16)}$

Chewing simulation test parameters: Vertical movement: $3 \mathrm{~mm}$ Horizontal movement: $1 \mathrm{~mm}$ Rising speed: $90 \mathrm{~mm} / \mathrm{s}$ Forward speed: $90 \mathrm{~mm} / \mathrm{s}$. Descending speed: $40 \mathrm{~mm} / \mathrm{s}$. Backward speed: 40 $\mathrm{mm} / \mathrm{s}$. Cycle frequency $1.6 \mathrm{~Hz}$. Weight per sample: $5 \mathrm{~kg}$ Torque; 2.4 N.m.

The vertical marginal gap distance for all samples were subsequently remeasured after the fatigue loading testing using the same method described previously. All Data were statistically analyzed.

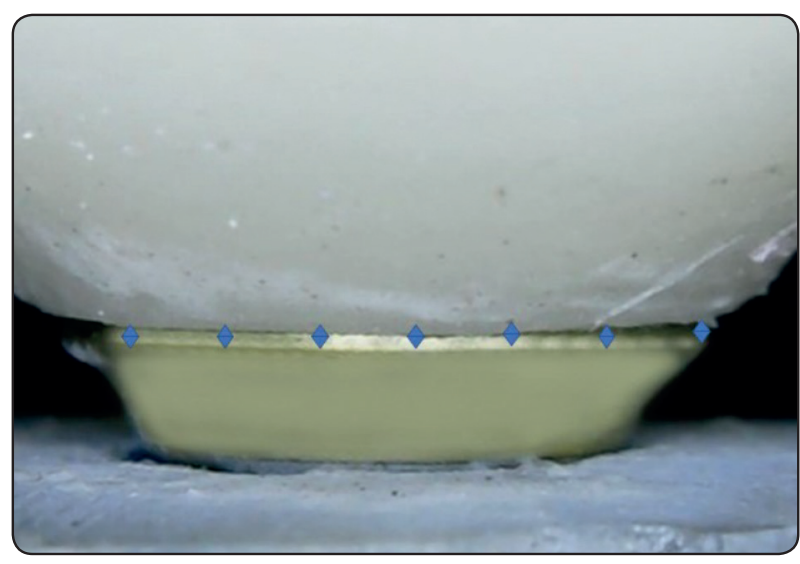

Fig. (3): Lines of measurements at equidistant points.

\section{Statistical Analysis}

The results were analyzed using graph pad instat (Graph Pad, Inc.soft ware for windows. A value of $\mathrm{P}<0.05$ was considered statistically significant continuous variables were expressed as the mean 
and standard deviation. After homogeneity of variance and normal distribution of errors had been confirmed, one -way analysis of variance was performed. Student t-test was done for compared pairs. Two- way ANOVA was performed to detect effect of each factor (material and aging).sample size $(n=5)$ was large enough to detect large effect sizes for main effects and pair-wise comparisons, with the satisfactory level of power set at $80 \%$ and a 95\% confidence level.

\section{RESULTS}

\section{Marginal gap distance:}

Marginal gap $(\mu \mathrm{m})$ results showing mean, standard deviation (SD) values for all groups before and after fatigue loading (mechanical aging) are summarized in table (2) and graphically drawn in figure (4).

\section{Effect of material group on marginal gap;}

As regard to the total marginal gap distance either before or after fatigue cyclic loading; there was a statistically significant difference beween the four different ceramic types as indicated by two-way ANOVA test $(\mathrm{P}=0.0013<0.05)$. The total marginal gap mean values were highest for CD group followed by f.explore group then V. enamic group while the lowest marginal gap mean value was recorded with e.max group. Pair-wise Tukey's post-hoc test showed non-significant $(\mathrm{p}>0.05)$ difference between (CD and f.Explore) (V. enamic and e.max), (V.enamic and f.explore) and as shown in table (2) and figure (4).

\section{Effect of fatigue loading on marginal gap;}

Irrespective of material type, The total marginal gap mean values with all types of ceramics were higher after aging than before and this was statistically significant as demonstrated by twofactors ANOVA test $(\mathrm{P}=<0.0001<0.05)$, table (2) and figure (4).
TABLE (2) Marginal gap results (Mean values \pm SDs) for all groups before and after fatigue loading.

\begin{tabular}{|c|c|c|c|c|c|}
\hline & \multicolumn{2}{|l|}{ Variable } & \multicolumn{2}{|c|}{$\begin{array}{l}\text { Mechanical } \\
\text { aging }\end{array}$} & \multirow{2}{*}{\begin{tabular}{|c|} 
Statistics \\
t-test \\
P value \\
\end{tabular}} \\
\hline & & & Before & After & \\
\hline & $\boldsymbol{V}$ & Mean & $59.85^{\text {в }}$ & $73.35^{\mathrm{B}}$ & $00150 \%$ \\
\hline & V. Enamic & $\pm S D$ & \pm 6.142 & \pm 9.71 & $0.015 Z^{\prime}$ \\
\hline & & Mean & $58.58^{\text {в }}$ & $72.44^{\mathrm{B}}$ & $00162 *$ \\
\hline Material & e.max & $\pm S D$ & \pm 7.82 & \pm 9.11 & 0.0105 \\
\hline type & Cel & Mean & $75.38^{\mathrm{A}}$ & $98.78^{\mathrm{A}}$ & 0001 \\
\hline & Centra & $\pm S D$ & \pm 13.46 & \pm 10.40 & $0.0014^{\circ}$ \\
\hline & F Exnlore & Mean & $74.47^{\mathrm{A}}$ & $85.48^{\mathrm{A}}$ & $00539 \mathrm{~ns}$ \\
\hline & & $\pm S D$ & \pm 11.30 & \pm 7.56 & \\
\hline Statistics & ANOVA & P value & $0.0254 *$ & $0.001 *$ & \\
\hline
\end{tabular}

Different letters in same column indicating significant between groups $(p<0.05)$

*; significant $(p<0.05) \quad n s ;$ non-significant $(p>0.05)$

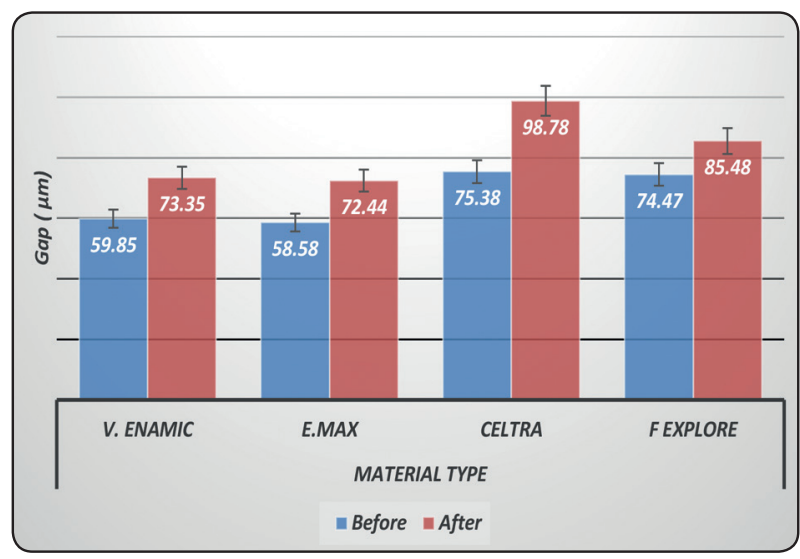

Fig. (4): Column chart of marginal gap mean values for all groups before and after fatigue loading

\section{DISCUSSION}

The null hypothesis of this study was rejected as there is statistically significant difference between the four ceramic materials used in this study concerning the vertical marginal gap measurements; also there is a significant difference between the vertical marginal gap measurements before and after fatigue loading. 
Marginal precision is an important measure for fixed prosthodontics. ${ }^{(16)}$ Material type , fabrication technique and fatigue loading are among the factors that can distress marginal accuracy. Artificial aging is vital part of an in vitro study as boring pressures during mastication may lead to critical crack growth in ceramic materials. ${ }^{(17)}$

In this study, all specimens were subjected to dynamic loading and thermal cycling to examine specimen behavior under clinically simulated conditions. ${ }^{(18)}$

Different CAD-CAM materials were selected for this study in order to help clinicians to select the system capable of producing the best marginal fit.

In this study, marginal fit was evaluated by direct viewing with external measurements using digital microscope at fixed magnification of $35 \mathrm{x}$ before and after fatigue loading. This technique has the benefits of non-invasive, precise and reproducible measurements and is therefore, useful to determine the accurate fit of the entire specimen margins. ${ }^{(19,20)}$

For standardization, implant Abutment with 4.5 diameter, $4.0 \mathrm{~mm}$ abutment length and $8^{\circ}$ convergence angle was used to act out the mandibular first molar form to obtain a ceramic restoration.

In the current study, the cement space was customed to be 50 microns on CAD-CAM software, though 30 to $50 \mu \mathrm{m}$ was found to offer the best marginal fitting. ${ }^{(21)}$

Nowadays, there are numerous restorative $\mathrm{CAD} /$ CAM materials differ in their chemical structure and manufacture process. Some of these materials, requiring specific machine for sintering and glazing after milling, ${ }^{(22,23)}$ while others only need finishing and polishing. (24) variances in the construction process and tools needed may possibly affect marginal and internal adaptations of restorations.

In the current study, there is significant difference in marginal precision of all tested ceramic materials; this came in agreement with many studies ${ }^{(25-27)}$ who ascribed this to the technical hitches concerning scanning, the milling process from different ceramic blocks burs used in each milling machine, and material mechanical property and type used. ${ }^{(28-31)}$.

McLean and von Fraunhofer ${ }^{(32)}$ reported that a restoration is considered clinically successful when the marginal discrepancy and the luting space is less than $120 \mathrm{~mm}$. The current study showed that the marginal accuracy of all tested groups was within this range and can be considered clinically acceptable.

In the existing study; $\mathrm{CD}$ crowns showed higher mean vertical marginal gap than did e. max crowns, which came in accordance with the previously studies; ${ }^{33-35)}$ this difference could be due to the prevalence of very small breaks in the cervical region during milling of $\mathrm{CD}$ crowns, possibly due to the presence of $10 \%$ zirconia in the microstructure thus increasing the strength. A previous study ${ }^{(36)}$ showed CD were approximately 10-30\% higher tangential forces than LD. Moreover, margin inaccuracy may be related to the increased brittleness index and chipping factor of $\mathrm{CD}$, resulting in greater marginal gap. The percentage of chipping factor is the ratio of the total amount of chipping around the marginal circumference of the restoration multiplied by 10027 . It is definitely related to the brittleness index, which is a ratio of hardness and fracture toughness. A higher hardness value and lower fracture toughness value increase the brittleness index of a material, indicating that it is more prone to chipping ${ }^{(33,34,37)}$. According to the manufacturers of the materials used in this study, CD has a higher hardness value than does LDS in crystallized mode (7000 vs. 5600 $\mathrm{MPa})$, and a lower fracture toughness value $(2.00$ vs. 2.25 MPa m-0.5).

As shown in table 2 the mean marginal discrepancy of f. explores crowns was higher significantly than e.max CAD, this came with the results of Gold A. et al ${ }^{(38)}$ and Güngör B. et $\mathrm{al}^{(39)}$. The authors 
attributed this excessive marginal gap to sinterization shrinkage of thick zirconia material of the full contour monolithic zirconia crowns a fact that may lead to significantly more sintering contraction. Another study ${ }^{(40)}$ recognized this difference in the marginal gap due to the variances between Carbide milling tools that were used to mill zirconia blocks versus diamond tools that were used for e.max blocks. Authors ${ }^{(25-27,40)}$ added that ; the milling process of zirconia blanks were prepared in a dry field whereas e.max blocks were milled in a wet field. This difference in milling atmosphere explains the variance in marginal precision values made.

In the present study the mean marginal vertical marginal gap of the hybrid V.enamic was insignificantly different from that of E.max CAD both recording the least marginal gap. The results of current study are in the agreement with a study by Majeed MA. et $\mathrm{al}^{(26)}$, who compared the marginal accuracy of full contour CAD/CAM crowns constructed from four different ceramic materials ; zirconia, lithium disilicate, zirconia-reinforced lithium silicate and hybrid dental ceramic. They found that the best marginal fit was shown by vita Enamic crowns. Authors attributed this result to the material science innovation, as hybrid dental ceramics were not exposed to added stages as sintering or crystallization after the milling process. (41) On the other hand; Gawad A. et $\mathrm{al}^{(42)}$ found that the mean marginal discrepancy of the hybrid vita Enamic was statistically significantly lower than that of E.max CAD subgroups. Authors ascribed this difference to the difference in materials' physical properties. Since vita Enamic blocks are softer than lithium disilicate CAD/CAM blocks. Thus, they can be milled faster and easily than LD.

There was a statistically significant increase in the vertical marginal gap distance values after cyclic fatigue loading with all types of ceramics except for f.explore used in the present study. The significant increase in the marginal gap after cyclic fatigue loading with all ceramic types came in agreement with numerous in vitro studies. ${ }^{(43,44)}$ Hung et al. ${ }^{(45)}$ and Krejci et al.(46) demonstrated a significant negative effect of thermal and mechanical cycling on marginal fit of crowns; the authors described that the frequent masticatory forces lead to worsening of the marginal integrity of adhesively luted crowns. The thermal and mechanical load cycles could yield significant stresses on the restorations interface causing cement interface failure. The repeated mastication forces and the differences in thermal expansion between cement and restoration may further deteriorate marginal adaptation. ${ }^{(47,48)}$ This came in contradiction with Hamza ${ }^{(29)}$ and Beschnidt and Strub ${ }^{(49)}$ who found that there was no significant difference on marginal fit found between different ceramic types before and after aging.

F.explore zirconia marginal gap didn't affected by fatigue loading this come in accordance with Sorentinno R. ${ }^{(50)}$; who were evaluated the tetragonalto-monoclinic $(\mathrm{t}-\mathrm{m})$ transformation of zirconia with different marginal preparations immediately after milling and after chewing simulation (simulating one year of clinical service) using the microRaman spectroscopic analyses. The authors stated that; zirconia crowns did not show any sign of $t-m$ transformation, either in the load application areas or at the margins after a one-year chewing simulation.

\section{CONCLUSIONS}

Within the limitations of the study, the following conclusions were drawn:

1. All Monolithic CAD/CAM ceramic materials shown clinically adequate marginal adaptations.

2. V. Enamic and Lithium disilicate (e.max CAD) provided better marginal fit than Celtra Duo and f.explore zirconia.

3. Cyclic loading had a detrimental effect in the vertical marginal gap distance for all ceramic types except f.explore zirconia. 


\section{ACKNOWLEDGEMENT}

The author would like to thank Ivory Trade International Co. the dealer for Upcera Company in the Egyptian market for supplying Functional Explore zirconia disks for this research.

\section{REFERENCES}

1. Pjetursson BE, Sailer I, Zwahlen M, Hämmerle CH. A systematic review of the survival and complication rates of all ceramic and metal-ceramic reconstructions after an observation period of at least 3 years. Part I: Single crowns. Clin OralImplants Res 2007; 18:73-85.

2. Raigrodski AJ, Hillstead MB, Meng GK, Chung KH. Survivaland complications of zirconia-based fixed dental prostheses: a systematic review. J Prosthet Dent 2012;107:170-7.

3. Sailer I, Makarov NA, Thoma DS, Zwahlen M, Pjetursson BE. All-ceramic or metal-ceramic tooth-supported fixed dental prostheses (FDPs)? A systematic review of the survival and complication rates. Part I: Single crowns (SCs). Dent Mater 2015;31:603-23.

4. Miyazaki T, Nakamura T, Matsumura H, Ban S, Kobayashi T. Current status of zirconia restoration. J Prosthodont Res 2013;57:236-61.2-5 from2

5. Gracis S, Thompson Van P, Ferencz J L, Silva N R F A, Bonfante E A. A New Classification System for AllCeramic and Ceramic-like Restorative Materials. Int J Prosthodont 2015; (28) 3, 227-235.

6. Santos MJ, Costa MD, Rubo JH, Pegoraro LF, Santos GC Jr. Current all-ceramic systems in dentistry: a review. Compend Contin Educ Dent. 2015;36(1):31-37.

7. Sundh A, Sjogren G. A comparison of fracture strength of yttrium- oxide-partially stabilized zirconia ceramic crowns with varying core thickness, shapes and veneer ceramics. Journal of Oral rehabilitation 2004; 31:682-8.

8. Nawafleh N, Hatamleh M, Elshiyab S and Mack F, Lithium Disilicate Restorations Fatigue Testing Parameters: A Systematic Review Journal of Prosthodontics 2016; 25:116-126.

9. Chitmongkolsuk S, Heydecke G, Stappert C. Fracture strength of all-ceramic lithium disilicate and porcelain fused-to-metal bridges for molar replacement after dynamic loading. Eur. J. Prosthodont Restor Dent 2002; 10:15-22.
10. Ueda K, Güth JF, Erdelt K, Stimmelmayr M, Kappert H, Beuer F. Light transmittance by a multi-coloured zirconia material. Dent Mater J. 2015;34(3):310-314.

11. Kurbad A, Kurbad S . A new, hybrid material for minimally invasive restorations in clinical use. Int J Comput Dent 2013; 16(1):69-79.

12. Coldea A1, Swain MV, Thiel N. Mechanical properties of polymer-infiltrated-ceramic-network materials. Dent Mater. 2013; 29(4):419-426.

13. Gonzalo E, Suarez MJ, Serrano B, Lozano JFL. A comparison of the marginal vertical discrepancies of zirconium and metal ceramic posterior fixed dental prostheses before and after cementation. J Prosthet Dent 2009;102:378-384.

14. Jacobs MS, Windeler AS. An investigation of dental luting cement solubility as a function of the marginal gap. $\mathrm{J}$ Prosthet Dent 1991;65: 436-442.

15. Cosyn J, Van Aelst L, Collaert B, Persson GR, De Bruyn H. The periimplant sulcus compared with internal implant and suprastructure components: A microbiological analysis. Clin Implant Dent Relat Res 2011;13:286-295.

16. Quintas AF, Oliveira F, Bottino MA. Vertical marginal discrepancy of ceramic copings with different ceramic materials, finish lines, and luting agents: an in vitro evaluation. J Prosthet Dent 2004;92:250-7.

17. Hamza $T$ and shereif $R$ In vitro evaluation of marginal discrepancy of monolithic zirconia restorations fabricated with different CAD-CAM systems J Prosthet Dent 2017; 117:762-766.

18. Güngör MB, Nemli SK. Fracture resistance of CAD-CAM monolithic ceramic and veneered zirconia molar crowns after aging in a mastication simulator. J Prosthet Dent. 2018;119:473-480. 26 from 29

19. Prisco R, Cozzolino G, Vigolo P. Dimensional accuracy of an epoxy die material using different polymerization methods. Journal of prosthodontics: official journal of the American College of Prosthodontists. 2009;18(2):156-61.

20. Att H, Komine F, Gerds T, Strub J. Marginal adaptation of three different zirconium dioxide three unit fixed dental prostheses. J Prosthet Comlekoglu Dent. 2009; 101: 239-47.

21. Nakamura T, Dei N, Kojima T, Wakabayashi K. Marginal and internal fit of Cerec $3 \mathrm{CAD} / \mathrm{CAM}$ all-ceramic crowns. Int J Prosthodont 2003; 16:244-8.

22. Ng J, Ruse D, Wyatt C. A comparison of the marginal fit of crowns fabricated with digital and conventional methods. J Prosthet Dent 2014;112:555-60. 
23. Awada A, Nathanson D. Mechanical properties of resinceramic CAD/CAM restorative materials. J Prosthet Dent 2015; 114:587-93.

24. Chen HY, Hickel R, Setcos JC, Kunzelmann KH. Effects of surface finish and fatigue testing on the fracture strength of CAD-CAM and pressed-ceramic crowns. J Prosthet Dent 1999;82:468-75.

25. Park SH. and Lee KB. A comparison of the fidelity between various cores fabricated with CAD/CAM system. J Kor Acad Prosthodont 2008; 43: 269-78.

26. Majeed MA. and Al-Adel SK. Evaluation of the marginal and internal fitness of full contour CAD/CAM crowns made from zirconia, lithium disilicate, zirconia-reinforced lithium silicate and hybrid dental ceramic by silicone replica technique (A comparative In vitro study). Journal of Gene c Environ. Resour. Conserva on 2016, 4:10-20.

27. Boitelle P, Mawussi B., Tapie L., Fromentine O. A systematic review of CAD/CAM ft restoration evaluations. J. Oral. Rehabil 2012;41;853-74.

28. Rashad TM, Abdou AM. Fracture resistance of three different all-ceramic crown systems. Egy Dent J.2001; 47: 933.

29. Guazzato, M., Albakry M., Simon P. Ringer, S. P., and Michael V. Swain, M. V.: Strength, fracture toughness and microstructure of a selection of all-ceramic materials. Part II. Zirconia-based dental ceramics. Dent. Mater. 2004; 20: 449-56.

30. Fleming G J P., Nolan L., and Harris J. The in-vitro clinical failure of all-ceramic crowns and the connector area of fixed partial dentures: the influence of interfacial surface roughness. J. Dent.2005;33:405-12.

31. Papadiochou S, Pissiotis AL. Marginal adaptation and CAD-CAM technology: A systematic review of restorative material and fabrication techniques. J Prosthet Dent. 2017.

32. McLean JW, von Fraunhofer JA. The estimation of cement film thickness by an vivo technique. Br Dent J 1971;131:107-11.

33. Tinschert, J.; Natt, G.; Mautsch, W.; Augthun, M.; Spiekermann, H. Fracture resistance of lithium disilicate-, alumina, and zirconia-based three-unit fixed partial dentures: A laboratory study. Int. J. Prosthodont. 2001, 14, 231-238.

34. Anadioti, E.; Aquilino, S.A.; Gratton, D.G.; Holloway, J.A.; Denry, I.; Thomas, G.W.; Qian, F. 3D and 2D Marginal Fit of Pressed and CAD/CAM Lithium Disilicate
Crowns Made from Digital and Conventional Impressions. J. Prosthodont. 2014, 23, 610-617.

35. Chai, H.; Lawn, B.R.A universal relation for edge chipping from sharp contacts in brittle materials: A simple means of toughness evaluation. Acta Mater. 2007, 55, 2555-2561.

36. Chen, X.P.; Xiang, Z.X.; Song, X.F.; Yin,L. Machinability: Zirconia-reinforced lithium silicate glass ceramic versus lithium disilicate glass ceramic. J. Mech. Behav. Biomed. Mater. 2020, 101, 103435 .

37. Chavali, R.; Nejat, A.H.; Lawson, N.C. Machinability of CAD-CAM materials. J. Prosthet. Dent. 2017, 118,194199.

38. Gold SA, DA-Costa JB, Ferracae JL. Effect of Crystallization Firing on Marginal Fit of Lithium Disilicate Crowns. IADR/AADR/CADR General Session and exhibition USA 2013.

39. Güngör MB, Doğan A, Turhan Bal BT, Nemli SK Evaluation of marginal and internal adaptations of posterior all-ceramic crowns fabricated with chair-side CAD/CAM system: an in vitro study. Acta Odontol Turc 2018; 35:1-8.

40. Pyo S., Kim D, Han J and Luke Yeo: Ceramic Materials and Technologies Applied to Digital Works in ImplantSupported Restorative Dentistry Materials 2020, 13, 1964.

41. A. Coldea, M. V. Swain, and N. Thiel, Mechanical properties of polymer-infiltrated-ceramic-network materials. Dental Materials, vol. 29, no. 4, pp. 419-426, 2013.

42. Gawad A., El Yassaky M, Fathi A., Hossam El Din M : Micro computed tomographic evaluation of marginal fit of different monolithic all ceramic crowns fabricated using two CAD/CAM systems:ADJ-for girls, 2019; 6(2):P 195201.

43. Guess PC, Zavanelli RA, Silva NR, Bonfante EA, Coelho PG, Thompson VP. Monolithic CAD/CAM lithium disilicate versus veneered Y-TZP crowns: comparison of failure modes and reliability after fatigue. Inter J Prosthod. 2010;23.

44. Alghazzawi TF, Lemons J, Liu P-R, Essig ME, Janowski GM. The failure load of CAD/CAM generated zirconia and glass-ceramic laminate veneers with different preparation designs. The J prosthet dent. 2012;108:386-393.

45. Hung SH, Hung KS, Eick JD, et al. Marginal fit of porcelain-fused-to metal and two types of ceramic crowns. J Prosthet Dent. 1990;63(1): 26-31. 
46. Krejci I, Mueller E, Lutz F. Effects of thermocycling and occlusal force on adhesive composite crowns. J Dent Res. 1994;73(6):1228-1232.

47. Rosentritt M, Sikora M, Behr M, Handel G. In vitro fracture resistance and marginal adaptation of metallic and toothcoloured post systems. J Oral Rehabil. 2004;31(7):675-681.

48. Blatz MB, Oppes S, Chiche $\mathrm{G}$, et al. Influence of cementation technique on fracture strength and leakage of alumina all-ceramic crowns after cyclic loading. Quintessence Int J. 2008;39:23-32.
49. Beschnidt SM, Strub JR. Evaluation of the marginal accuracy of different all-ceramic crown systems after simulation in the artificial mouth. J Oral Rehabil. 1999;26(7):582-593.

50. Sorrentino R, Navarra C, Di Lenarda R, Breschi L, Zarone F., Cadenaro 2 and Spagnuolo G.: Effects of Finish Line Design and Fatigue Cyclic Loading on Phase Transformation of Zirconia Dental Ceramics: A Qualitative Micro-Raman Spectroscopic Analysis Materials 2019, 12, 863. 